TABLE VI

\begin{tabular}{|c|c|c|c|c|}
\hline Name & Age ! & Disability & Previous occupation & Present vocational program \\
\hline M.M. & 24 & Cauda equina & Farmer (Kibbutz) & $\begin{array}{l}\text { Learned to drive-works } \\
\text { in factory (Kibbutz) }\end{array}$ \\
\hline A.D. & 22 & Tetraplegia & $\begin{array}{l}\text { Medical student } \\
\text { (freshman) }\end{array}$ & $\begin{array}{l}\text { Learning English, study- } \\
\text { ing Maths. University } \\
\text { - towards work with } \\
\text { computer }\end{array}$ \\
\hline D.P. & 20 & Paraplegia & $\begin{array}{l}\text { Electronic } \\
\text { technician }\end{array}$ & $\begin{array}{l}\text { Studying electronic } \\
\text { engineering }\end{array}$ \\
\hline M.K. & 20 & Paraplegia & Student of biology & Back at previous studies \\
\hline B.G. & 23 & Cauda equina & $\begin{array}{l}\text { Studied engineer- } \\
\text { ing }\end{array}$ & $\begin{array}{l}\text { Learned to drive, back at } \\
\text { previous studies }\end{array}$ \\
\hline Y.S. & 28 & Monoparesis & Farmer (Kibbutz) & Back at previous work \\
\hline L.A. & 21 & $\begin{array}{l}\text { Brown-Séquard } \\
\text { syndrome }\end{array}$ & $\begin{array}{l}\text { Soldier-Regular } \\
\text { army }\end{array}$ & Not known \\
\hline A.H. & 22 & Cauda equina & $\begin{array}{l}\text { Light industry- } \\
\text { volunteer }\end{array}$ & Studying Hebrew \\
\hline M.I. & $19 \frac{1}{2}$ & Paraplegia & $\begin{array}{l}\text { Soldier-Regular } \\
\text { army }\end{array}$ & Started driving lessons \\
\hline
\end{tabular}

\title{
STABILISATION OF THE SPINE IN TRAUMATIC PARAPLEGIA
}

By Alexander M. Katznelson, B.S., M.D.

Orthopedic Department Tel-Hashomer Hospital, and the Medical School of Tel Aviv University

IN traumatic paraplegia we have a condition wherein there is an acute damage to the spinal cord.

In man the spinal cord lies within a fluid bed surrounded by its membranes and is protected by the bony structure of the spine, which is formed anteriorly by the vertebral body, laterally by the pedicles, and the laminae form the posterior portion. This is not a solid tube, for to permit motion there are two sets of joints. The amphiarthrodial joints which are connected by intervening discs of fibro- 
cartilage, and by diarthrodial joints which are more freely mobile and are found in the posterior section of the vertebra. The vertebral bodies are bound one to another by the anterior and posterior longitudinal ligaments, and the neural arch is bound to its adjacent fellow by the ligamentum flavum, the interspinous and supraspinous ligaments.

Movement is greatest in the cervical and lumbar regions and it is restricted in the thoracic region. It is in the mobile regions that one sees the most damage due to fractures, and this is the most frequent area for injuries to the spinal cord.

This paper refers to the injuries and treatment of patients who suffered damage to the spinal cord in the thoraco-lumbar region, namely fractures of the vertebrae lying between Th. 9 and lumbar 2 .

Within the dura of this area, as opposed to the region of the neck and thorax, where there is one form of nervous tissue, we have nervous tissues of two types. This is due to the discrepancy in the length of the cord in relation to the vertebral column; for we have a shorter spinal cord which terminates opposite the lower border of the Ist lumbar vertebral body. Within this area we have the sacral cord surrounded by the roots of the lumbar segment. These two forms of nervous tissue differ histologically, functionally and also respond differently to trauma. The spinal cord is very susceptible to injury with no power of regeneration, whereas the spinal roots are more sturdy and are less liable to irreversible damage. These nervous elements have different physiological functions to perform: the upper lumbar roots $L_{1}$ to L2 innervate flexors and adductors of the hip, then there is the extensor of the knee $\left(\mathrm{L}_{3}\right)$ while the lower lumbar roots innervate extensors and abductors of the hip. The sacral roots innervate the plantar flexors of the foot and ankle and also bowel and bladder function.

When the spine is injured there is a local disruption of some or all of the elements-there is a comminution with displacement of the vertebral body, rupture of the intervertebral disc, fractures of the pedicles, tearing of the muscles and ligaments resulting in an encroachment of the spinal canal and the intervertebral foramen, causing pressure onto the nervous system.

There are two schools of thought as to the treatment. In the non-operative, one presumes that the cord injury is complete and that the damage is irreparable, and that the associated fracture is such that if treated conservatively it will in due course form a stable bony mass. If surgery is performed and the area be approached from the back with the object of decompression, then the stripping of the sacrospinalis together with the exposure of the spinal cord and the removal of the laminae and ligaments (ligamentum flavum, interspinous and supraspinous) will remove all of the stability to the spine, and the spinal cord will be subject to strains, stretching, torsion, etc. Therefore if surgery is performed without an attempt at operative stabilisation, then catastrophe, rather than benefit is to follow.

On the other hand we know that a comminuted injury of the vertebra and its component parts can cause cord or root compression, which may be irreversible if left alone, and can regain physiological function if the deformity be removed, and is followed by an efficient method of stabilisation. This not only allows a functional improvement, but it relieves pain and permits easier nursing.

During the past five years we have used the method of decompression and internal fixation of $\mathrm{I} 3$ patients with traumatic paraplegia and on one patient where cord compression was due to a metastatic adeno-carcinoma.

Two surgical methods were employed for this purpose. The former by dual- 
plate fixation, whereby the metallic plates were anchored at the base of the spinous processes, both above and below the area of the laminectomy. The results were favourable, in that stability permitted easier nursing, but these patients were kept recumbent until there was roentgenographic evidence of callus formation of the fracture. In most of these patients, the dual plates remained stable, but no correction of the angulation of the long axis of the spine was possible. In one patient (E. S.) where a Meurig-Williams plate was applied before he came under our care, we found it had avulsed from its lower point of fixation in the spinous process.

This is in keeping with a report of F. R. Zadik (1959) wherein be quotes Sir Ludwig Guttmann who in a personal communication reported the avulsion of the dual plate with loss of fixation in several patients.

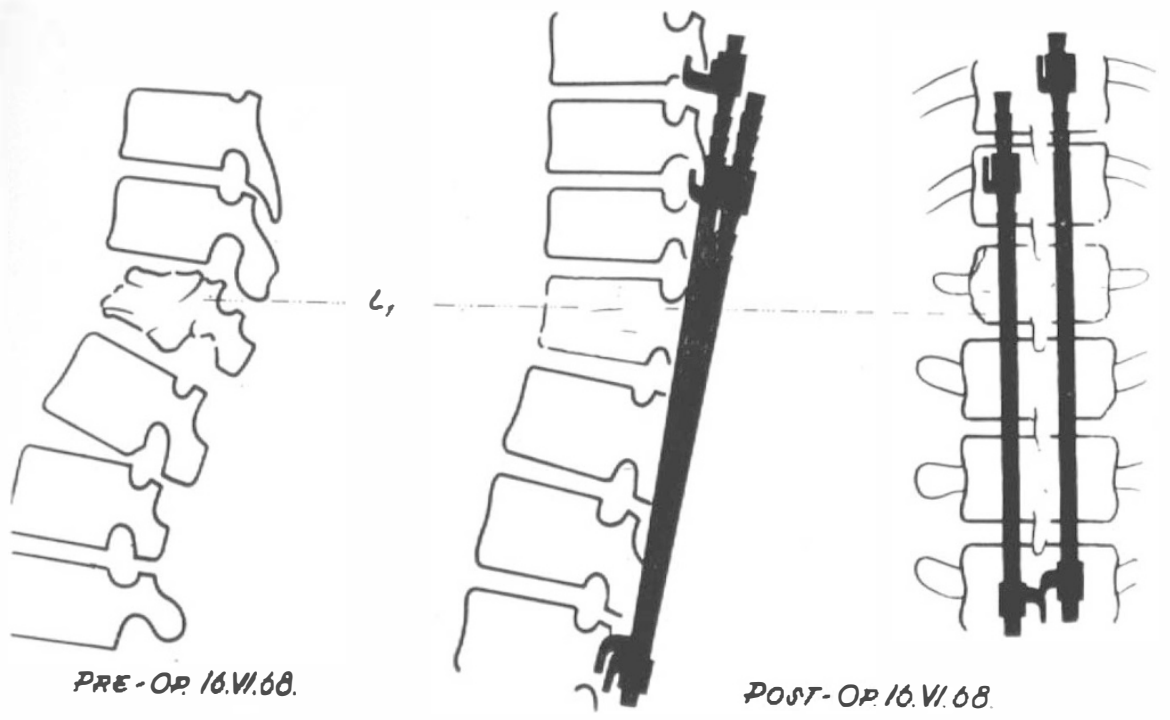

FIG. I

Diagramatic illustration of the method used to attain stability of the fractured spine.

It also illustrates the raising of the compressed vertebral body.

In our series in one patient in spite of an adequate decompression and fixation by the dual plate we had an increase of angulation from 30 degrees to 50 degrees within a period of seven months. In spite of this, in this same patient there was an improvement of his neurological status (A. N.).

In recent years a new surgical technique has been developed by $P$. $R$. Harrington of Houston whereby one is able to attach strong metal rods to the pedicles and laminae, and thus is able to cause a distraction and reposition of the fractured spine (fig. I). It was estimated that with properly applied distracting hooks the points of attachment in the pedicles and intact laminae can bear a weight of between 100 and $300 \mathrm{lb}$./sq. in. There is also a mechanical advantage in that with the metallic purchase on the pedicle and lamina they are closer to the vertebral body than is the dual plate which is attached to the base of the spinous process. These distracting rods are available in various lengths so as to be of optimal length to fit each spine, and they may be bent during the operation so as to fit the curvature of the spine. 
Following the insertion of the metallic rods, the area about the laminectomy is stripped of cortical bone, and if necessary the dissection is extended laterally to expose the transverse processes. Over this whole area of decorticated bone, bony slivers are laid, so as to achieve a solid bony fusion.

We have had occasion to have used this method on nine patients, all of whom underwent surgery without any complications. On all occasions the local damage found was very extensive and was more than could be estimated by the X-ray (for

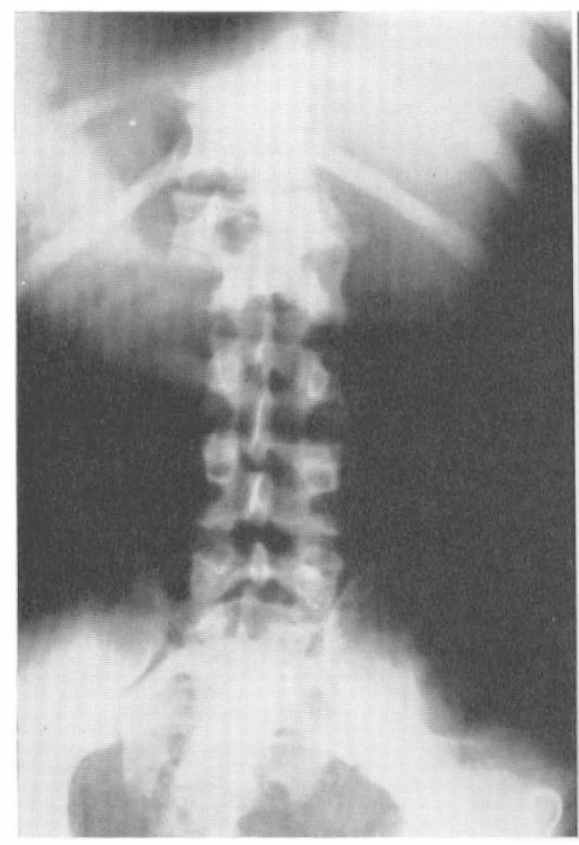

FIG. 2

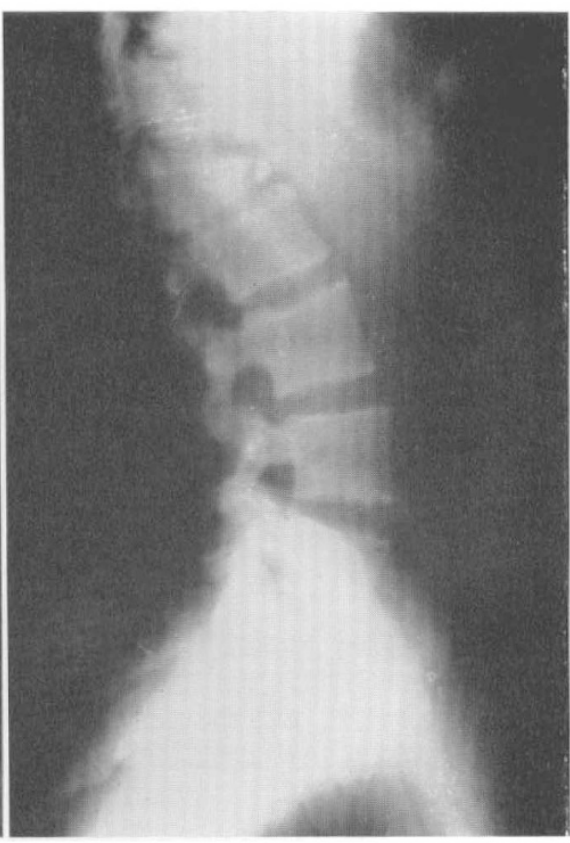

Fig. 3

Fig. 2.-Anterior-posterior view of the fractured spine, showing the rotation of the body $\mathrm{LI}_{\mathrm{I}}$ in relation to $\mathrm{L} 2$, and the displacement of the thoracic spine in relation to the lumbar spine.

Fig. 3.-Lateral view of the lumbar spine showing the severe compression of the anterior segment of the first lumbar vertebral body, and the posterior displacement of the spine, at the $\mathrm{L}_{1}$ to $\mathrm{L}_{2}$ level. With impingement onto the intervertebral foramen at $\mathrm{LI}_{\mathrm{I}}$ to $\mathrm{L} 2$.

one must remember that a patient with an acute traumatic paraplegia is not the ideal patient for diagnostic radiography). On two occasions it was necessary to remove part of the posteriorly protruding vertebral body to relieve the tension from the spinal cord. In most of these patients the rods were anchored two vertebrae above and two below the level of the injury, and in this way we had achieved a stable spine.

These patients were able to become ambulatory rather early. This is too small a series to draw conclusions as to the neurological benefit, for not all the factors are identical. Not all of these patients were operated on the day of their 
arrival, and in some it is too early since their injury is recent. Nevertheless no patient is worse as a result of the treatment, and in most there is an improvement of two dermatomes, which in this area permits the use of the hip flexor.

From the static point of view the stability obtained is adequate and early ambulation is possible.

As an example of the patients treated with Harrington's distracting rods the following case is described:

History. S. A., male, age 19 , sustained a compressed fracture of the body of $\mathrm{LI}_{\mathrm{I}}$, with a severe destruction of the involved vertebra. The history as given by the patient was that he had fallen off a horse-cart while the latter was in motion.

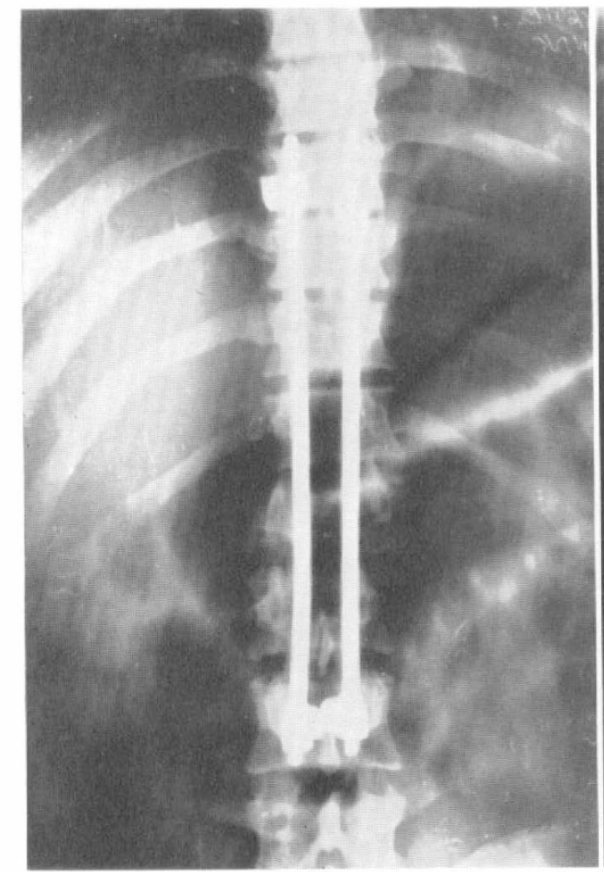

FIG. 4

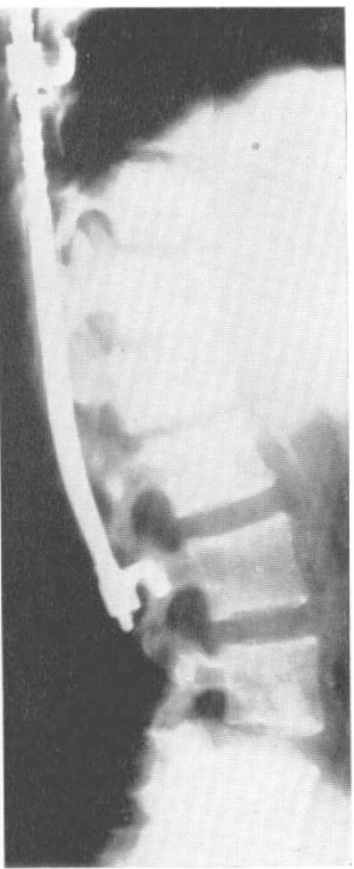

FIG. 5

Figures 4 and 5 show the resultant position. The laminectomy of ThI 2 and LI, the total alignment of the spine, and the restoration of the height of the body of LI.

On admission a few hours following his fall, he was in good general condition, not in shock, with a motor and sensory defect at the level of L2. Figures 2 and 3 show the condition of the fracture-dislocation.

A surgical decompression of the cord was performed of the laminae DI2 and $\mathrm{L}_{\mathrm{I}}$, exposing the cord which was found to be intact, but stretched taut over the adjacent fractured vertebral body. There was no dural pulse.

Twin Harrington rods were inserted between the vertebrae D9 and $\mathrm{L}_{3}$, and simultaneously a spinal fusion was performed over the same area.

The immediate post-operative course was uneventful. Within one month the neurological level descended to $\mathrm{L}_{4}$, and he became ambulatory with the aid of crutches. Figures 4 and 5 show the reduction and expansion of the fractured vertebra. 